\title{
Personality and Network Factors: Impact of Predispositions and Network Heterogenity on Civic Participation
}

\author{
Zuoming Wang ${ }^{1}$, Xia Tang ${ }^{2}$ \\ ${ }^{1}$ Associate Professor at Department of Communication Studies, University of North Texas, United States \\ ${ }^{2}$ Associate Professor in College of Teacher Education, Capital Normal University, China \\ Correspondence: Xia Tang, Associate Professor in College of Teacher Education, Capital Normal University, China.
}

Received: July 22, 2019

doi:10.11114/smc.v7i2.4398
Accepted: September 1, $2019 \quad$ Online Published: September 9, 2019

URL: https://doi.org/10.11114/smc.v7i2.4398

\begin{abstract}
This paper links predispositions and structural influences on civic participation by exploring the relationship among personality strength, network size, network heterogeneity, and political tolerance, as well as their direct and indirect impact on civic participation. Results from a national telephone survey $(n=694)$ show political tolerance has a positive effect on political participation. The effect of personality strength on civic participation is mediated through discussion networks. Although personality strength has a negative effect on political tolerance, it boosts both the size of individual's discussion network and the heterogeneity of this network. Moreover, network heterogeneity indirectly facilitates civic participation by increasing political knowledge and tolerance.
\end{abstract}

Keywords: personality strength, network size, network heterogeneity, civic participation

\section{Introduction}

Derived from a sociological perspective, interpersonal discussion networks have been recognized as an important explanatory structural influence on civic participation (Leighley, 1990; Weimann, 1982). Most scholars have focused on two dimensions of discussion networks and their influence on information dissemination and participatory behavior: network size and network heterogeneity (Campbell, Marsden, \& Hurlbert, 1986; Leighley, 1990; McLeod, Scheufele, Moy, et al., 1999).

While most scholars agree that there is a link between network characteristics and participatory behavior, however, there is significant disagreement about what this relationship looks like. Some claim that network heterogeneity is a critical component of truly deliberative democracy. That is, the encounter and exchange of diverse opinions promote the exchange of diverse perspectives, tolerance and civic engagement which are so essential to a well-functioning democracy (e.g. McLeod, et al., 1999; Scheufele, Nisbet, Brossard, \& Nisbet, 2004). These findings, however, are inconsistent with a second line of research that assumes that heterogeneous discussion networks are also related to increased cross-pressures from non-likeminded others and - as a result - increased apathy among citizens (e.g. Lazarsfeld, Berelson, \& Gaudet, 1944; Mutz, 2002b). The obvious discrepancy between these two lines of reasoning has remained largely unresolved. This study therefore seeks to explain the processes through which network heterogeneity is related to political activity or inactivity. In particular, it links individual predispositions and structural influences, especially interpersonal discussion networks, to civic participation. In our analyses, we account for the contribution of major demographic variables (age, gender, education) and individual predisposition (personality strength), as well as the mediating roles of media use (newspaper and television hard news use), and discussion networks on civic participation. Furthermore, we explore the relationship among personality strength, network size and network heterogeneity. Most importantly, we explicate the differential roles of network size and network heterogeneity on political tolerance as well as their relative contribution to the production of civic participation.

\subsection{Personality Strength}

As outlined earlier, this study is concerned with the relative influence of predispositional and structural variables on political participation. More specifically, recent research has highlighted the importance of personality strength as a key variable in promoting and sustaining levels of political participation (e.g. Scheufele \& Shah, 2000; Shah \& Scheufele, 2006). This literature has used "personality strength" and "opinion leadership" as synonymous or at least largely 
overlapping constructs. An opinion leader is defined as a "a person who exerts influence on the opinions of others" (Hellevik \& Bjorklund, 1991, p.158). Katz and Lazarsfeld (1955) offered a similar definition of opinion leaders whom they labeled "general influentials"or "experts:" "a personal in whom one has confidence and whose opinions are held in high regard" (p.140). According to Scheufele and Shah (2000), "personality strength is conceived to be a feature of individuals, a reflection of their confidence in leadership role, their aptitude at shaping others' opinions, and their self-perceived impact on social and political outcomes" (p.109). Based on these great similarities between the concepts of personality strength and opinion leadership, these two concepts are often used interchangeably (Weimann, 1991, 1994).

Research on personality strength (or opinion leadership) shows that opinion leaders have more interpersonal contacts and can access a richer resource of communication network than non-leaders (Katz \& Lazarsfeld, 1955; Weimann, 1991). Based on that, we hypothesized the following:

H1: Personality strength will be positively related to interpersonal discussion networks. That is, people with higher personality strength will have larger and more heterogeneous discussion networks.

The definition of opinion leadership implies that opinion leaders are more concerned about civic issues, which subsequently leads them to be exposed to mass media message more than non-leaders and to transmit those message to others (Katz, 1957). Empirical studies found that the effects of personality strength on civic engagement may also be mediated through media use (Noelle-Neumann, 1999; Weimann, 1994). Moreover, media use was found to be a key mediator for the SES-participation link identified in previous research, indicating that demographic variables work through news consumption (as well as other variables) to influence political participation (McLeod et al., 1999; Scheufele \& Shah, 2000; Verba, Schlozman, \& Brady, 1995). Based on these findings, we hypothesized the following:

H2: Personality strength will be positively related to media use. That is, people with higher personality strength will consume more hard news, both in newspaper and on TV.

As outlined earlier, personality strength is of key interest in the study of civic participation (Noelle-Neumann, 1999). Prior research has revealed that opinion leaders are more concerned about the issue, have higher levels of knowledge, and are more active in participating in political activities than non-leaders (e.g. Lazarsfeld, et al., 1944; Noelle-Neumann, 1999; Weimann, 1994). The link between personality strength and civic participation can be direct (Weimann, 1994) as well as indirect, as we argue, mediated through other variables such as media use and discussion network. Consistent with this literature, we hypothesized the following:

H3: Personality strength will be positively related to political knowledge.

H4: Personality strength will be positively related to civic participation.

\subsection{Role of Interpersonal Discussion and Opinion Leadership}

In previous studies, personality strength has been examined as a dispositional trait (e.g. Noelle-Neumann, 1999; Scheufele \& Shah, 2000; Shah \& Scheufele, 2006). However, Rokeach (1960) noted, "a field-theoretical position requires a consideration of both personal and situational conditions, and their interactions, as determinants of behavior. A sole concern with personality ignores the role of the present context; a sole concern with the present context leaves us with the embarrassment of individual differences. In recent years, there has been a good deal of criticism from both social psychologists and sociologists regarding the one-sidedness of personality approaches to social issues. This criticism is to some extent justified" (p.401, 402). This argument has been supported by the empirical studies of context's impact on political participation. For instance, regardless of individual characteristics, individuals living in low-status neighborhoods are found to consistently more likely to vote for the left-wing or working-class party than are those living in high-status neighborhoods (Butler \& Stokes, 1974; Huckfeldt, 1986; Langton \& Rapoport, 1975; Miller, 1956; Putnam, 1966). Moreover, "vote preferences are socially structured, not only by the characteristics of the voter, but also by the characteristics and preferences of others with whom the voter discusses politics" (Huckfeldt \& Sprague, 1991, p.156). All these suggest that dispositional traits are not the only determinants of social behaviors, and social contexts also play an important role in promoting variables, such as political participation.

Research on social networks has witnessed a growing interest in personal networks as channels for dissemination of information and influence (Weimann, 1982). The process of communication flow is determined jointly by the personal traits of communicators and the structural positions of them in the social network (Weimann, 1982). The theoretical assumption is that social interactions not only expose individuals to social norms of political behavior, but also increase individuals' knowledge about participation opportunities. Therefore, "including social interaction in models of political participation provides a more appropriate specification of what causes individuals to become involved in politics" (Leighley, 1990, p.460). Based on this reasoning, we argue that the relationship between personality strength and other situational factors such as interpersonal discussion and media use deserves more attention. 
Previous research examined the influence of personality strength on civic engagement and found that personality strength, an amalgam of self-confidence and opinion leadership, has a relatively strong direct impact on civic engagement, which is not mediated by interests and media use (Scheufele \& Shah, 2000). However, these studies have not included interpersonal discussion in the model. Communication behaviors include not only hard news media use but also interpersonal discussion. It is through interaction with others that the opinion leaders exert their influence on non-leaders and shape public opinion (Katz \& Lazarsfeld, 1955).

The classic opinion leadership research conducted by Katz and Lazarsfeld (1955) pointed out that "the traditional image of the mass persuasion process must make room for 'people' as intervening factors between the stimuli of the media and resultant opinions, decisions and actions" (p.32, 33). They not only discovered the phenomenon of opinion leadership, but also made it quite explicit that "opinion leadership is not a trait which some people have and others do not, but rather that opinion leadership is an integral part of the give-and-take of everyday personal relationships" (p.33). They claimed, "Even an individual's seemingly personal opinions and attitudes may be by-products of interpersonal relations" (p.65). Interestingly, instead of regarding the concept of opinion leadership as a predetermined and unchangeable dispositional trait like other scholars (e.g. Noelle-Neumann, 1999; Scheufele \& Shah, 2000), Katz and Lazarsfeld studied opinion leadership as a volatile factor within the framework of interpersonal relationships. They further suggested, "all interpersonal relations are potential networks of communication and that an opinion leader can best be thought of as a group member playing a key communications role" (p.33). All these pointed to the possible connection between opinion leadership and the interpersonal communication network, which has been ignored in the prior studies of the effect of personality strength on political participation. Based on these rationales, we argue that interpersonal discussion could be a mediator for the link between personality strength and civic participation.

\subsection{Network Heterogeneity and Network Size}

As noted before, both predispositions and social context are determinants of political behaviors. Social interaction is often analyzed in light of the individual's political discussion network (Weatherford, 1982). Thus, two characteristics, size and heterogeneity, of individuals' social networks deserve more attention. The size of discussion network is often identified as the number of individuals with whom the respondent reports having had discussions, and network heterogeneity, also called as network diversity, is often referred to as the extent to which individuals are exposed to conflicting opinions or positions about politics (Leighley, 1990).

Researchers have employed measures of diversity and size to describe the characteristics (what Campbell et al. called the "range") of the discussion network. Some researchers (e.g. Campbell et al., 1986; Laumann, 1973) focused directly on network heterogeneity (or diversity), while others (e.g. Scheufele et al., 2004; Shah \& Scheufele, 2006) examined the network size. Campbell and his colleagues (1986) pointed out measures of discussion networks based on size follow from the assumption "that larger networks represent greater diversity; as the number of persons in a network increases, the homogeneity of alters' attributes declines" (p.102). However, this assumption is highly questionable. The "homogenizing effects on network diversity" has been detected in different components of social networks, including race (e.g. Farley, 1984), age (Lofland, 1970), and occupation and education (Hawley, 1981; Simkus, 1978). Katz and Lazarsfeld (1955) discussed "the tendency of people with like opinions and values to seek each other out as companions" (p.59, italics in original). Huckfeldt and Sprague (1991) claimed "people exercise discretion in the choice of a discussion partner, but that choice is circumscribed by the structurally determined availability of like-minded individuals" (p.156). Echoing this argument, Mutz (2001) argued "to the extent that people live among homogeneous others in self-selected enclaves, their exposure to dissimilar views may be limited" (p.97). She further pointed out there is a "persistent trade-off between amount of interaction and heterogeneity of interaction" (p. 98). Based on these, we argue that heterogeneity and size are two distinct components of discussion networks, and they are not necessarily correlated positively. The concept of network size mirrors the width of interpersonal discussion scope, but does not necessarily reflect how diverse the viewpoints that individuals encounter in the political conversation are. Therefore, we expect mechanisms for network size and network heterogeneity to work on political tolerance and civic participation may be different.

The role of discussion network size and network heterogeneity on political participation has become the focus of debate recently. Empirical studies have revealed inconsistency on the effect of the discussion network heterogeneity on civic participation. Some claim that network heterogeneity is the key determinant of deliberative democracy. That is, the encounter and exchange of diverse opinions promote perspective-taking, tolerance (Mutz, 2002a) and civic engagement (e.g. McLeod et al., 1999; Scheufele et al., 2004). McLeod and his colleagues (1996, 1999) found that network heterogeneity directly increases participation in public forums. Consistently, Leighley (1990) found that network heterogeneity (he framed it the "conflict in the political network") is positively related to both voting turnout and contacting. However, ambivalence studies show that network heterogeneity increases the disagreement among citizens, which subsequently hinders political participation (e.g. Lazarsfeld et al., 1944; Mutz, 2002b). Mutz (2002b) found 
people whose networks involve greater political disagreement are less likely to participate in politics. She further offered two social psychological processes to explain this effect: "first, those embedded in cross-cutting social and political networks are, as a consequence, more likely to hold ambivalent political views, which in turn discourage political involvement. Second, social accountability pressures in cross-cutting networks discourage political participation" (p.838).

With regard to the effect of network size on civic participation, Leighley (1990) claimed that the size and homogeneity of individuals' social networks are considered to be stimulants of political participation. He further argued that the probability of being exposed to other individuals who are politically active increases with the increase of individuals' discussion network size, and he found a positive relationship between network size and political participation. McLeod and his associates (1996) also found that network size has a positive effect on institutional activities, public forum attendance, and community involvement. Later, McLeod et al. (1999) found that network size has an indirect positive effect on political participation through network heterogeneity.

Although the effect of network size on civic participation is generally positive, its impact on political tolerance is less optimistic. Mutz (2002a) found that the number of discussants and density of the discussion networks have no effect on political tolerance, while exposure to dissonant views has indirect positive effects on political tolerance through "awareness of rationales for oppositional views" and "intimacy within dissonant dyads."

Taking together, the concept of discussion networks is less explored as a social determinant of tolerance. The extant literature suggests that there is a positive effect of network heterogeneity on political tolerance, while the relationship between network size and tolerance is less clear. Noticing the inconsistency among various discussion network studies, we posed the following hypotheses and research questions:

H5: Network heterogeneity will be positively related to political tolerance.

H6: Network size will be positively related to civic participation.

$\mathrm{RQ} 2$ : What is the relationship between network heterogeneity and civic participation?

RQ3: What is the relationship between network size and political tolerance?

The effect of media use on promoting political knowledge and civic participation are frequently detected (McLeod, et al., 1996; 1999; Scheufele \& Shah, 2000; Scheufele, et al., 2004; Shah \& Scheufele, 2006). The positive relationship between political knowledge, tolerance, and civic participation are also well-documented (e.g. Mutz, 2002b). Consistent with the extant literature, we hypothesized the following:

H7a: Newspaper hard news use will be positively related to political knowledge.

H7b: Television hard news use will be positively related to political knowledge.

H8a: Newspaper hard news use will be positively related to civic participation.

H8b: Television hard news use will be positively related to civic participation.

H9: Political knowledge will be positively related to political tolerance.

H10: Political knowledge will be positively related to civic participation.

H11: Political tolerance will be positively related to civic participation.

Finally, political tolerance is likely linked to opinion leadership directly. Research has revealed three major categories of determinants for political tolerance: "social (education, social status, age, religion), psychological (self-esteem, authoritarianism, dogmatism, trust, value actualization), and political (ideology, perceptions of threats, support for the general norms of democracy, political information and involvement)" (Gibson, 1987, p.431). As an attribute of individual traits, personality strength falls into the second category, which is constituted by a host of personality attributes. Among them, self-esteem predicts tolerance (McClosky \& Brill, 1983; Sniderman, 1975), and trust is positively related to tolerance (Gibson, 1987), while authoritarianism, dogmatism, or "closed-mindedness" are negatively related to tolerance (Sullivan, Piereson, \& Marcus, 1982).

Some research found that opinion leaders are more tolerant than the ordinary mass public (e.g. Gibson \& Bingham, 1985; McClosky \& Brill, 1983; Nunn, Crockett, \& Williams, 1978; Stouffer, 1955). However, Sniderman and his colleagues (1996) did not detect this positive relationship. Moreover, when taking the multifaceted predispositions of opinion leaders into account, it is too early to conclude that opinion leaders are definitely more tolerant than others. Bockman and Gayk (1977) found that opinion leaders felt more efficacious about the impact they personally could have on political processes, which suggests opinion leaders are feeling good about being influentials in general. This argument was supported by the research on volunteerism and other helping behaviors, which suggest that "to feel good [and] boost self-esteem" is the primary motive for participation (Omoto \& Snyder, 1995, p.671; Schaller \& Cialdini, 
1988). Interestingly, Bockman and Gayk (1977) also found that many of the opinion leaders and communication leaders also maintain a low trust orientation (towards political elites) and envision an aggressive democratic ideology. Moreover, the diffusion of innovation studies reveal that opinion leaders deviate less from group norms than the average group members (Rogers \& Cartano, 1962). Meanwhile it is "marginals," peripheral in the network system, rather than the opinion leaders, who tend to be the early innovators (Rogers, 1962; Rogers \& Kincaid, 1981), which casts doubt on the assumption that opinion leaders are more open-minded than others. The multiple traits of opinion leaders detected by previous empirical studies pose a question: When the opinion leaders are confronted with dissimilar viewpoints and their self-esteem are challenged, are they more tolerant than non-leaders, or it is the other way around? In other words, the question, "Are the opinion leaders more dogmatic or open-minded?" has remained unanswered in the prior literature. Given the multifaceted characteristics of opinion leaders, we are interested in the following research question:

RQ1: What is the relationship between personality strength and political tolerance?

\section{Method}

Data for our study came from a national telephone survey of 694 adults conducted in 2018 (RDD sampling, response rate: 58\%) in USA. In order to ensure a true probability sample that would allow generalization to the larger population, multiple call-backs were made to all respondents over the course of one month in order to minimize non-response biases.

\subsection{Measures}

Exogenous Variables: Exogenous demographic controls include age $(\mathrm{M}=50.08, \mathrm{SD}=17.16)$, gender $(54.8 \%$ female $)$ with females coded 0 and males coded 1 , and education $(\mathrm{M}=14.63, \mathrm{SD}=2.95)$.

\subsubsection{Antecedent Endogenous Variables}

Our measure of personality strength $(\mathrm{M}=6.83, \mathrm{SD}=1.86)$ was a: 4-item 10-point scale adapted from Noelle-Neumann's self-designating technique (see Appendix for question wording). The reliability was Cronbach's alpha $=.78$. Individual network heterogeneity $(\mathrm{M}=17.1, \mathrm{SD}=9.5)$ was derived from a battery of questions measuring the social setting of people's political conversation (see Scheufele et al., 2004) and also from previous measures of discussion network heterogeneity (Scheufele et al., 2004). Respondents were asked how frequently they discussed politics with 1) men, 2) women, 3) people with extreme right views, 4) people with extreme left views, 5) people who are Democrats, 6) people who are Republicans, and 7) people of a different race or ethnicity on a ten-point scale. Based on these items, a discussion heterogeneity scale was constructed with higher scores reflecting greater heterogeneity in political discussion partners across the dimensions of gender, ideology, political identification, and race/ethnicity. That is, respondents received an individual network heterogeneity score based on how often respondents talked to dissimilar others on politics. For example, male respondents were re-coded as scoring " 0 " for the frequency of discussion with men, and female respondents were re-coded as scoring " 0 " for discussion with women, assuming ostensibly that discussion of politics with members of the same sex leads to no net gain in gender dissimilarity. Democrats who discussed politics with other Democrats were coded "0" for that discussion item, and the same was done for Republicans who discussed political issues or candidates with other Republicans. This matching technique was also done for ideology. Extreme liberals who discussed politics with extreme liberals received a score of zero, and the same was done for conservatives. All the items were then totaled into a combined index. Individual network size $(\mathrm{M}=3.21, \mathrm{SD}=2.94)$ was derived from the same battery for network heterogeneity. For each of the seven questions in that battery, we recoded answers less than 6 (as the frequency they discussed politics with this particular type of people) to 0 , that is, we did not considered these particular types of people as part of the respondent's discussion network; and we recoded answers more than 6 (as the frequency they discussed politics with this particular type of people) to 1 , that is, we considered it as part of the respondent's discussion network. The recoded score for each of the seven types of people were added up for each respondent. Thus, we came up with a scale with higher scores reflecting larger interpersonal discussion network across the dimensions of gender, ideology, political identification, and race/ethnicity. Media use was broken down by medium. Newspaper hard news use $(\mathrm{M}=2.40, \mathrm{SD}=4.95)$ was measured by combining two 10-point scales tapping people's level of attention to international and national hard news $(r=.66)$. Similarly, the television hard news use $(\mathrm{M}=12.04$, $\mathrm{SD}=5.35)$ was a combination of two 10-point scales tapping attention to the two content areas on television $(r=.72)$. Political knowledge $(\mathrm{M}=2.61, \mathrm{SD}=1.25$, alpha $=.63)$ was an additive index that consisted of four questions tapping correct identification of political figures and governmental decision-making processes (i.e. name of vice-president, role of supreme court, required percentage of Congress to override presidential veto, majority party in House of Representatives). Political tolerance was measured based on two tolerance measures included in our data set. A random half of the sample $(n=379)$ received a content-specific tolerance measure using the least-liked group (Sullivan et a., 1982) and the other half of the sample $(n=402)$ received a GSS tolerance measure (Stouffer, 1955). Respondents receiving content-specific tolerance measure were asked whether they would grant seven types of civic rights to 
member of the group they liked least in society (yes coded as 1 , no coded as 0 ). The number of civic rights respondents allows their least-liked group to have were used as their tolerance score. Respondents received the GSS tolerance measure were asked whether they would grant the same seven types of civic rights to members of five different groups of people (atheists, communists, racists, militarists and homosexuals) (yes coded as 1, no coded as 0). The number of civic rights respondents allows different types of groups to have were used as their tolerance score. These two sets of tolerance score were standardized, so that they can be compared to each other.

\subsubsection{Consequence Endogenous Variable}

Political participation $(\mathrm{M}=2.4, \mathrm{SD}=1.93$, alpha= .72$)$ was measured by a cumulative index of nine dichotomous items that asked respondents if they have, in the last two years, attended a meeting, written a letter-to-the-editor, circulated a petition, voted for an elected official, worked for a political campaign, called other people to raise funds for a campaign, contributed money to a political organization, or persuaded someone to vote either for or against a candidate or issue.

\subsection{Generating the Model}

In order to establish the interconnections among all the above variables, we tested a theoretical model of structural relationships among these variables against our data using LISREL (Jöreskog, 1993). LISREL allows for the simultaneous estimation of all parameters in a model. This model accounted not only for all the links from exogenous and endogenous variables to the dependent variable but also for the relationships among all exogenous and antecedent endogenous variables. Any given coefficient therefore represents the relationship between two variables, controlling for all other relationships and variables in the model. By treating endogenous variables as both independent and dependent variables, structural equation modeling allows for the estimation of direct and indirect effects. In this study, we followed the "model generating" approach (Jöreskog \& Sörbom, 1996). According to this approach, we developed an initial theoretical model and tested it with empirical data, then adjusted the model by freeing or fixing some of the paths based on the Lagrangian Multiplier (LM) test (Bollen, 1987) to optimize the model fit.

\section{Results}

In order to establish the interconnections between personality strength, network size, network heterogeneity, media use, political knowledge, political tolerance, and political participation, we tested a theoretically-driven model of structural relationships among these variables against our data. This model accounts not only for all the links from exogenous and endogenous variables to the dependent variable but also for the relationships among all exogenous and antecedent endogenous variables.

The model fit the data exceptionally well with a Chi-Square of $18.61(\underline{\mathrm{df}}=21, \underline{\mathrm{N}}=694)$ that translated into a BIC statistic of -121.25. The Goodness-of-Fit Index (GFI) and the Adjusted-Goodness-of-Fit Index - controlling for multivariate non-normality - were both close to perfect with values of 1.00 and .99 , respectively. The model explains $25 \%$ of the variance of political knowledge, $14 \%$ variance of tolerance, and 30\% variance of political participation. 


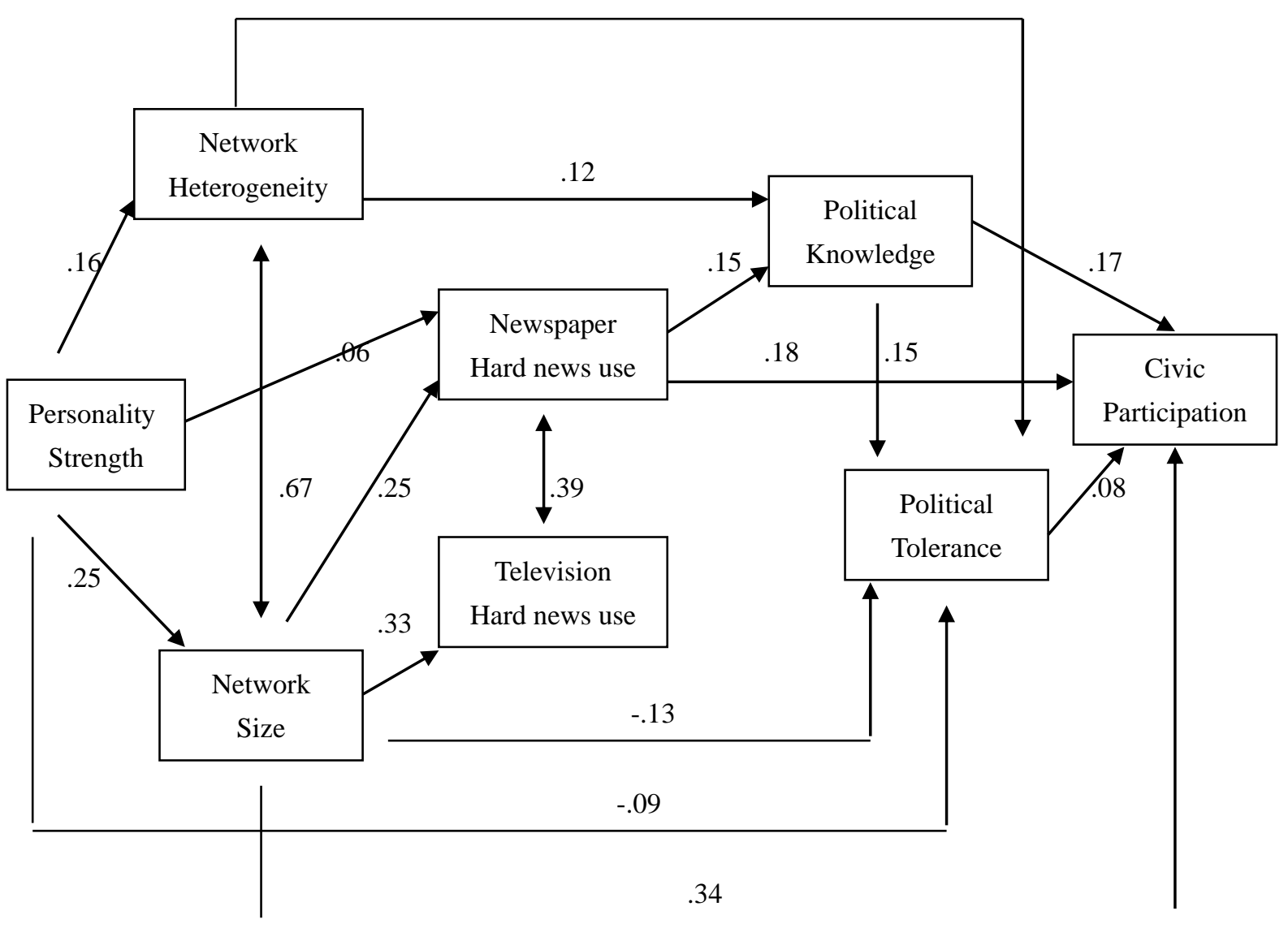

Figure 1. Structural model (demographic information controlled for): the full sample (N=694)

As is apparent from Figure 1, most of the predicted paths were statistically significant and in the hypothesized direction. The exceptions are the expected link between personality strength and television hard news use $(\mathrm{H} 2)$, between personality strength and political knowledge $(\mathrm{H} 3)$, between personality strength and civic participation (H4), between TV hard news use and political knowledge (H7b), between TV hard news use and civic participation (H8b). Although direct relationships between these variables were not observed, indirect effects were detected providing support for these hypothesized links (except for H7b, H8b, the effect of TV hard news use). 
Table 1. Influence of exogeneous variables on other variables in the model: the full sample (N=694)

\begin{tabular}{llll}
\hline & Age & $\begin{array}{l}\text { Gender } \\
\text { (male) }\end{array}$ & Education \\
\hline \multirow{2}{*}{ Personality Strength } & --- & --- & .35 \\
Network Size & --- & --- & --- \\
& --- & -- & .35 \\
Network Heterogeneity & -.12 & --- & .22 \\
& --- & --- & .09 \\
Newspaper hard news use & -.12 & --- & .31 \\
& -.25 & --- & .17 \\
Television hard news use & --- & --- & .06 \\
& -.25 & --- & .23 \\
Political knowledge & .23 & --- & --- \\
& -.03 & --- & .10 \\
Political tolerance & .20 & --- & .10 \\
& .17 & --- & --- \\
& -.04 & --- & .10 \\
& .13 & --- & .10 \\
& .10 & .20 & .32 \\
Civic participation & .00 & --- & .04 \\
& .10 & .20 & .36 \\
& -.19 & .09 & .27 \\
& -.01 & .03 & .02 \\
& -.20 & .12 & .29 \\
\hline
\end{tabular}

Notes: (1) All coefficients are significant at $\mathrm{p}<.05$.

(2) Coefficients in the first row indicate direct effects, coefficients on the second row indicate indirect effects, and coefficients on the third row indicate total effects. If the sum of direct and indirect effects is not equal to the total effect size, this is due to nonsignificant indirect effects, which are not shown here.

As Table 1 shows, older respondents were more likely to participate in political activities $(\gamma=.14)$, which is consistent with prior studies (e.g. Milbrath \& Goel, 1977; Nie, Verba, \& Petrocik, 1976; Wolfinger \& Rosenstone, 1980; Jennings \& Markus, 1988). Older respondents were also more likely to attend to hard news in newspaper $(\gamma=.23)$ and on television $(\gamma=.17)$, and to have higher level of political knowledge $(\gamma=.10)$. However, older respondents had a smaller $(\gamma=-.12)$ and a less heterogeneous interpersonal discussion network $(\gamma=-.25)$, and was less politically tolerant $(\gamma=-.19)$. Males had a higher level of political knowledge $(\gamma=.20)$ and slightly more political tolerant $(\gamma=.09)$. Highly educated respondents tended to exerted higher personality strength $(\gamma=.35)$. Consistent with Campbell et al.'s (1986) findings, we found highly educated respondents had a larger $(\gamma=.22)$ and more heterogeneous $(\gamma=.17)$ interpersonal discussion network. Meanwhile, highly educated respondents had a higher level of political knowledge $(\gamma=.32)$ and political tolerance $(\gamma=.27)$, which is consistent with Stouffer's (1955) findings. Table 1 also indicated that males were slightly more politically tolerant (indirect effect of .03) and slightly more active in political participation (indirect effect of .04). Similarly, an indirect link was found linking education and political participation (indirect effect of .21). That is, highly educated respondents were more likely to participate political activities, which replicated Leighley's (1990) findings. 
Table 2. Relationships among endogenous variables: the full sample $(\mathrm{N}=694)$

\begin{tabular}{|c|c|c|c|c|c|c|c|c|}
\hline & 1 & 2 & 3 & 4 & 5 & 6 & 7 & 8 \\
\hline \multirow{3}{*}{ Personality strength (1) } & -- & -- & -- & -- & -- & -- & -- & -- \\
\hline & -- & -- & -- & -- & -- & -- & -- & -- \\
\hline & -- & -- & -- & -- & -- & -- & -- & -- \\
\hline \multirow{3}{*}{ Network size (2) } & .25 & -- & -- & -- & -- & -- & -- & -- \\
\hline & -- & -- & -- & -- & -- & -- & -- & -- \\
\hline & .25 & -- & -- & -- & -- & -- & -- & -- \\
\hline \multirow{3}{*}{$\begin{array}{l}\text { Network Heterogeneity } \\
\text { (3) }\end{array}$} & .16 & -- & -- & -- & -- & -- & -- & -- \\
\hline & -- & -- & -- & -- & -- & -- & -- & -- \\
\hline & .16 & -- & -- & -- & -- & -- & -- & -- \\
\hline \multirow{4}{*}{$\begin{array}{l}\text { Newspaper hard news } \\
\text { use (4) }\end{array}$} & .06 & .25 & -- & -- & -- & -- & -- & -- \\
\hline & .06 & -- & -- & -- & -- & -- & -- & -- \\
\hline & .13 & .25 & -- & -- & -- & -- & -- & -- \\
\hline & --- & .33 & -- & -- & -- & -- & -- & -- \\
\hline \multirow[t]{3}{*}{ TV hard news use (5) } & .08 & -- & -- & -- & -- & -- & -- & -- \\
\hline & .08 & .33 & -- & -- & -- & -- & -- & -- \\
\hline & -- & & .12 & .15 & -- & -- & -- & -- \\
\hline \multirow[t]{3}{*}{ Political knowledge (6) } & .04 & .04 & -- & -- & -- & -- & -- & -- \\
\hline & .04 & .04 & .12 & .15 & -- & & -- & -- \\
\hline & -.09 & -.13 & .17 & -- & & .15 & -- & -- \\
\hline \multirow[t]{2}{*}{ Political tolerance (7) } & .00 & .01 & .02 & .02 & - & -- & -- & -- \\
\hline & -.09 & -.12 & .19 & .02 & & .15 & -- & -- \\
\hline \multirow{3}{*}{ Civic participation (8) } & --- & .34 & -- & .18 & & .17 & .08 & -- \\
\hline & .11 & .04 & .04 & .03 & - & .01 & -- & -- \\
\hline & .11 & .38 & .04 & .21 & & .18 & .08 & -- \\
\hline
\end{tabular}

Notes: (1) All coefficients are significant at $\mathrm{p}<.05$.

(2) Coefficients in the first row indicate direct effects, coefficients on the second row indicate indirect effects, and coefficients on the third row indicate total effects. If the sum of direct and indirect effects is not equal to the total effect size, this is due to nonsignificant indirect effects, which are not shown here.

As Table 2 shows, personality strength was directly related to the size $(\beta=.25)$ and the heterogeneity $(\beta=.16)$ of interpersonal discussion network, as well as newspaper hard news use $(\beta=.06)$. However, personality strength had a direct negative effect on political tolerance $(\beta=-.09)$. As a result of these direct links, personality strength exerted a positive indirect effect on political participation (indirect effect of .11). Respondents who had a larger discussion network also attended more to hard news in newspaper $(\beta=.25)$ and in television $(\beta=.33)$, as well as more active in political participation $(\beta=.34)$. However, interestingly, the network size had a negative direct effect on political tolerance $(\beta=-.13)$. Respondents who had a more heterogeneous discussion network had a higher level of political knowledge $(\beta=.12)$ and political tolerance $(\beta=.17)$. As a result of these direct links, the heterogeneity of interpersonal discussion network had a positive indirect effect on political participation (indirect effect of .04). For media use, the newspaper hard news use was directly related to political knowledge $(\beta=.15)$, political tolerance $(\beta=.02)$, and political participation $(\beta=.21)$. Political knowledge directly facilitated political tolerance $(\beta=.15)$ and political participation $(\beta=.18)$. Finally, political tolerance directly boosted political participation $(\beta=.08)$.

\section{Discussion}

This study examined two key questions. First, what is the role of opinion leadership in promoting political participation? Specifically, how does the personality strength relate to media use, network size, network heterogeneity, and political tolerance. Second, are there differences between network size and network heterogeneity with respect to their influence on political tolerance and civic participation? Consistent with Noelle-Neumann (1999) who has suggested that personality strength may be the key for understanding social capital, this study found that personality strength did 
promote civic participation. However, this positive relationship is not a direct link, as proposed by Scheufele and Shah (2000). Instead, it is an indirect effect, primarily mediated through interpersonal discussion (network size and network heterogeneity), which has been ignored in the prior studies. The mediating role of discussion network for the link personality strength and civic participation is one major findings of this research.

Moreover, we detected that personality strength is negatively related to political tolerance, suggesting although opinion leaders are more likely to engage in various forms of political activities, they are not "feeling good" when being challenged by dissonant views. This indicates the opinion leaders' strong defensive mindset through which information is filtered, in order to render harmless that which threats the ego. That is, opinion leaders are not necessarily more tolerant than non-leaders and they are not as open-minded as we thought before. This finding carries an important implication in real world. Treating personality strength as an inherent and fixed dispositional trait, researchers suggested that it's "more important to identify individuals with personality strength and direct resources toward them" (Scheufele \& Shah, 2000, p.125), for the purpose of reviving civic society. However, by placing personality strength in the context of interpersonal relations and identifying the important mediating role of discussion network for the personality strength---participation link, we argue that it's more important to widen the individuals' discussion network and promote the diversity of discussion network for the sake of fostering civic participation.

The differential role of network size and network heterogeneity on political tolerance is another major finding of this study. We disaggregate interpersonal discussion network into two components: network size and network heterogeneity. Although these two are highly interrelated $(r=.78, p<.001)$ in our data, they tap different aspects of the concept of discussion network. Even after controlling for each other, network size and network heterogeneity exert different influence on political tolerance. Consistent with Mutz's (2002a) finding that exposing individuals to dissimilar political views promotes their political tolerance, we found that the network heterogeneity does raise individual's tolerance level. The more diverse the network is, the more tolerance the individual is. On the contrary, the larger network size has a detrimental effect on tolerance. The larger the individuals' discussion network is, the less tolerant they are toward dissimilar viewpoints. This finding supports both Calhoun's (1988) claim that "political talk that centers on reinforcing a shared viewpoint does little to encourage deliberation on multiple perspectives or promote a public sphere" (p.220), and Katz and Lazarsfeld's (1955) assertion that people tend to seek out others with like opinions and values as companions. The differential role of network size and network heterogeneity on political tolerance suggests individuals are seeking for liked-minded others to talk about politics, and quite often the large discussion network contain most of discussants sharing the same viewpoints.

With regard to the effect on civic participation, we found network size directly promotes civic participation. This is consistent with prior studies (e.g. Leighley, 1990; Mutz, 2002b). This study did not detect a direct link between network heterogeneity and political participation, as proposed by some previous discussion network studies (e.g. McLeod et al., 1999; Scheufele \& Shah, 2000; Scheufele, et al., 2004; Shah \& Scheufele, 2006), instead, we found that network heterogeneity indirectly fosters civic participation by increasing political knowledge and political tolerance. This suggests that by adding network size into the model, the direct effect of network heterogeneity on civic participation is mediated.

A careful examination of the interpersonal discussion network studies reveals that not all discussion network studies contain both the network size and the network heterogeneity in their model (e.g. Scheufele et al., 2004) and the interrelationship between network size and network heterogeneity is not clear (e.g. Mutz, 2002b). Due to these fallacies, scholars could argue the size of discussion network may confound network heterogeneity when testing the latter's impact on civic participation. That is, the elevated civil participation could be attributed to network size, instead of the network heterogeneity. In order to solve that concern, in this study we proposed a correlational link between network size and network heterogeneity (psi coefficient $\psi=.67$ ). After parsing away the effect of network size, the network heterogeneity still maintains a positive influence on civic participation. Thus, we concluded that network heterogeneity is not automatically built into the concept of network size, and it is an important factor that fosters civic participation.

The effect of media use on civic participation was described as weak in the prior literature. However, this study rediscovers the importance of newspaper hard news use, which has a direct and relatively strong impact on civic participation (total effect .21). Putnam (1995) attributed the decline in social capital to the rise of television. However, this argument was not supported in this study. The effect of television hard news use on civic participation was not statistically significant. Consistent with Norris (1996), we found television is not the major cause for the decline in social capital.

\section{Conclusion}

Individuals' predispositions (personality strength) and the structural influence (discussion network) play a central role in determining whether citizens will internalize and apply the democratic principals of tolerance, and subsequently engage 
in civic activities. By combining these two important factors, this study enables us to understand more precisely how social networks help to translate personal recourses into civic participation. This paper explores the relationship among personality strength, the network size, the network heterogeneity, and tolerance, as well as their direct and indirect impact on civic participation. We found the effect of personality strength on civic participation is mediated through interpersonal discussion, which was ignored in the previous personality strength (or opinion leadership) studies. Therefore, we argue future research should explore personality strength in the context of social/interpersonal relations, instead of merely relying on the one-sidedness of personality approach.

Although the personality strength has a negative effect on political tolerance, it boosts both the size of individual's discussion network and the heterogeneity of this network. Moreover, the network size directly promotes civic participation, and the network heterogeneity indirectly facilitates civic participation via increasing political knowledge and political tolerance. However, the impacts of network size and network heterogeneity on political tolerance are sharply different. The network heterogeneity heightens individual's tolerance level. In contrast, the large network size has a detrimental effect on tolerance, which may be due to the fact that individuals are seeking for liked-minded others to talk about politics.

While after controlling the effect of network size, the network heterogeneity still maintains a positive influence on civic participation. This suggests network heterogeneity, which does not automatically built in the concept of network size, is an important factor fostering the civic participation.

\section{Acknowledgements}

This research was financially supported by China Scholarship Council and the Beijing Education Committee 2018 Social Science Plan (Grant NO. SM201810028016).

\section{References}

Bockman, S., \& Gayk, W. F. (1977). Political orientations and political ideologies. Pacific Sociological Review, 20, 536-552. https://doi.org/10.2307/1388714

Bollen, K. A. (1987). Total, direct, and indirect effects in structural equation models. In C. C. Clogg (Ed.), Sociological methodology 1987, Volume 17 (pp. 37-69). San Francisco, CA: Jossey-Bass. https://doi.org/10.2307/271028

Butler, D., \& Stokes, D. (1974). Political change in Britain: The evolution of electoral choice. New York: St. Martin's. https://doi.org/10.1007/978-1-349-02048-5

Campbell, K. E., Marsden, P. V., \& Hurlbert, J. S. (1986). Social resources and socioeconomic status. Social Networks, 8, 97-117. https://doi.org/10.1016/S0378-8733(86)80017-X

Farley, R. (1984). Blacks and Whites: Narrowing the gap? Cambridge. MA: Harvard University Press. https://doi.org/10.4159/harvard.9780674189225

Gibson, J. L. (1987). Homosexuals and the Ku Klux Klan: A contextual analysis of political tolerance. The Western Political Quarterly, 40, 427-448. https://doi.org/10.2307/448384

Gibson, J. L., \& Bingham, R. D. (1984). Skokie, Nazis, and the elitist theory of democracy. Western Political Quarterly, 37, 32-47. https://doi.org/10.2307/448324

Hawley, A. H. (1981). Urban society: An ecological approach. (2 ${ }^{\text {nd }}$ ed). New York: Wiley.

Hellevik, O., \& Bjorklund, T. (1991). Opinion leadership and political extremism. International Journal of Public Opinion Research, 3, 157-181. https://doi.org/10.1093/ijpor/3.2.157

Huckfeldt, R. (1986). Politics in context: Assimilation and conflict in urban neighborhoods. New York: Agathon.

Huckfeldt, R., \& Sprague, J. (1991). Discussant effects on vote choice: Intimacy, structure, and interdependence. Journal of Politics, 53, 122-158. https://doi.org/10.2307/2131724

Jenning, M. K., \& Markus, G. (1988). Political involvement in the alter years: A longitudinal study. American Journal of Political Science, 32, 302-316. https://doi.org/10.2307/2111125

Jöreskog, K. G. (1993). Testing structural equation models. In K. A. Bollen and J. S. Long (Eds.), Testing structural equation models (pp. 294-316). Newbury Park, CA: Sage.

Jöreskog, K. G., \& Sörbom, D. . (1996). LISREL 8: User's reference guide. Chicago, IL: Scientific Software International.

Katz, E. (1957). The two-step flow of communication: An up-to-date report on a hypothesis. Public Opinion Quarterly, 21, 61-78. https://doi.org/10.1086/266687 
Katz, E., \& Lazarsfeld, P. F. (1955). Personal Influence (pp.309-320). The Free Press, Glencoe, Illinois.

Langton, K. P., \& Rapoport, R. (1975). Social structure, social context, and partisan mobilization: Urban workers in Chile. Comparative Political Studies, 8, 318-344. https://doi.org/10.1177/001041407500800303

Laumann, E. O. (1973). Bonds of pluralism: The form and substance of urban social networks. New York: Wiley Interscience.

Lazarsfeld, P. F., Berelson, B., \& Gaudet, H. (1944). The people's choice: How the voter makes up his mind in a presidential campaign. New York: Columbia University Press.

Leighley, J. E. (1990). Social interaction and contextual influences on political participation. American Politics Quarterly, 18, 459-475. https://doi.org/10.1177/1532673X9001800404

Lofland, J. (1970). The youth ghetto. In Laumann, E. O., Siegel, P. M., \& Hodge, R. W. (Eds). The logic of social hierarchies. (pp. 756-778). Chicago: Markham.

McClosky, H., \& Brill, A. (1983). Dimensions of tolerance: What Americans believe about civil liberties. New York: Russell Sage Foundation.

McLeod, J. M., Daily, K. Guo, Z., Eveland, W. P. Jr., Bayer, J., Yang, S., \& Wang, S. (1996). Community integration, local media use, and democratic processes. Communication Research, 23, 179-209. https://doi.org/10.1177/009365096023002002

McLeod, J. M., Scheufele, D. A., Moy, P., Horowitz, E. M., Holbert, R. L., Zhang, W., ... Zubric, J. (1999). Understanding deliberation: The effects of discussion networks on participation in a public forum. Communication Research, 26, 743-774. https://doi.org/10.1177/009365099026006005

McLeod, J. M., Scheufele, E. A., \& Moy, P. (1999). Community, communication, and participation: The role of mass media and interpersonal discussion in local political participation. Political Communication, 16, 315-336. https://doi.org/10.1080/105846099198659

Milbrath, L. W., \& Goel, M. L. (1977). Political participation: How and why do people get involved in politics? Chicago: Rand McNally.

Miller, W. E. (1956). One party politics and the voter. American Political Science Review, 50, 707-725. https://doi.org/10.2307/1951554

Mutz, D. C. (2002a). Cross-cutting social networks: Testing democratic theory in practice. American Political Science Review, 96, 111-126. https://doi.org/10.1017/S0003055402004264

Mutz, D. C. (2002b). The consequences of cross-cutting networks for political participation. American Journal of Political Science, 46, 838-855. https://doi.org/10.2307/3088437

Nie, N. H., Verba, S., \& Petrocik, J. (1976). The changing American voter. Cambridge, MA: Harvard University Press.

Noelle-Neumann, E. (1999, September). Identifying opinion leaders. Paper presented to the $38^{\text {th }}$ annual convention of the European Society of Market Research, Wiesbaden, Germany.

Norris, P. (1996). Does Television erode social capital? A reply to Putnam. Political Science \& Politics, 29, 474-480. https://doi.org/10.1017/S104909650004511X

Nunn, C. Z., Crockett, H. J., \& Williams, J. A. (1978). Tolerance for nonconformity. San Francisco: Jossey-Bass.

Omoto, A. M., \& Snyder, M. (1995). Sustained helping without obligation: Motivation, longevity of service, and perceived attitude change among AIDS volunteers. Journal of Personality and Social Psychology, 68, 671-686. https://doi.org/10.1037/0022-3514.68.4.671

Putnam, R. D. (1966). Political attitudes and the local community. American Political Science Review, 60, 640-654. https://doi.org/10.2307/1952976

Putnam, R. D. (1995). Turning in, turning out: The strange disappearances of social capital in America. PS: Political Science and Politics, 28, 664-683. https://doi.org/10.1017/S1049096500058856

Rogers, E. M. (1962). Diffusion of innovations. New York: Free Press.

Rogers, E. M., \& Cartano, D. G. (1962). Methods of measuring opinion leadership. Public Opinion Quarterly, 26, 435-441. https://doi.org/10.1086/267118

Rogers, E. M., \& Kincaid, L. D. (1981). Communication networks. New York: Free Press.

Rokeach, M. (1960). Personality, ideology, and cognitive functioning. In M. Rokeach (Eds.) The open and closed minds: 
Investigations into the nature of belief systems and personality systems (pp.391-412). Basic Books, Inc: New York.

Schaller, M., \& Cialdini, R. B. (1988). The economics of empathic helping: Support for a mood management motive. Journal of Experimental Social Psychology, 24, 163-181. https://doi.org/10.1016/0022-1031(88)90019-4

Scheufele, D. A., \& Shah, D. V. (2000). Personality strength and social capital: The role of dispositional and informational variables in the production of civic participation. Communication Research, 27, 107-131. https://doi.org/10.1177/009365000027002001

Scheufele, D. A., Nisbet, M. C., Brossard, D., \& Nisbet, E. C. (2004). Social structure and citizenship: Examining the impacts of social setting, network heterogeneity and informational variables on political participation. Political Communication, 21,315-339. https://doi.org/10.1080/10584600490481389

Shah, D. V., \& Scheufele, D. A. (2006). Explicating opinion leadership: Non-political dispositions, information consumption, and civic participation. Political Communication, 23, 1-22. https://doi.org/10.1080/10584600500476932

Simkus, A. A. (1978). Residential segregation by occupation and race in ten urbanized areas, 1950-1970. American Sociological Review, 43, 81-93. https://doi.org/10.2307/2094763

Sniderman, P. M. (1975). Personality and democratic politics. Berkeley: University of California Press.

Sniderman, P. M., Fletcher, J. F., Russell, P. H., Tetlock, P. E. (1996). The clash of rights. New Haven, CT: Yale University Press.

Stouffer, S. (1955). Communism, conformity, and civic liberties. New York: Doubleday.

Sullivan, J. L., Piereson, J., \& Marcus, G. E. (1982). An alternative conceptualization of political tolerance: Illusory increases 1950s-1979s. The American Political Science Review, 73, 781-94. https://doi.org/10.2307/1955404

Verba, S., Schlozman, K. L., \& Brady, H. E. (1995). Voice and equality: Civic voluntarism in American politics. Cambridge, MA: Harvard University Press.

Weatherford, M. S. (1982). Interpersonal networks and political behavior. American Journal of Political Science, 26, 117-143. https://doi.org/10.2307/2110843

Weimann, G. (1982). On the importance of marginality: One more step into the two-step flow of communication. American Sociological Review, 47, 764-773. https://doi.org/10.2307/2095212

Weimann, G. (1991). The influentials: Back to the concept of opinion leaders. Public Opinion Quarterly, 55, $267-279$. https://doi.org/10.1086/269257

Weimann, G. (1994). The influentials: People who influence people. New York: State University of New York Press.

Wolfinger, R. E., \& Rosenstone, S. J. (1980). Who votes? New Haven, CT: Yale University Press.

\section{Copyrights}

Copyright for this article is retained by the author(s), with first publication rights granted to the journal.

This is an open-access article distributed under the terms and conditions of the Creative Commons Attribution license which permits unrestricted use, distribution, and reproduction in any medium, provided the original work is properly cited. 